\title{
GREEN AND BLUE INFRASTRUCTURES AS THE STRUCTURE OF A BIOREGION: THE CASE OF THE PONTINA BIOREGION
}

\author{
ALBERTO BUDONI ${ }^{1} \&$ LIANA RICCI ${ }^{2}$ \\ ${ }^{1}$ La Sapienza University of Rome, Italy \\ ${ }^{2}$ University College Dublin, Ireland
}

\begin{abstract}
European Commission (2013) defined Green and Blue infrastructures as a strategically planned network of natural and semi-natural areas designed and managed to provide a wide range of ecosystem services. They constitute an important reference for building effective approaches to urban and regional planning if integrated in the bioregional vision. A vision that starting from Berg's founding contribution has developed in various countries and in Italy through the territorialist school of Magnaghi. The idea of bioregion is based on the co-evolutionary relationship between humans and nature which requires transdisciplinary research work. This work can refer to two key concepts: structural invariant and accessibility. The first considers natural elements and anthropic "sediments" that characterise the landscape by combining nature and culture. The second concerns the way in which human beings move and use, interact and enjoy living in a space. The fruition of the physical space, the ecological and mobility networks together with the analysis of the security perception, affordability, and beauty/wellbeing for the human beings can be understood within the green and blue infrastructures system as the structure of a bioregion. In particular, the water represents a natural resource where the nature-human interaction needs to be particularly well managed to ensure sustainable and inclusive blue and green infrastructures. The competitive uses of water and the over exploitation of water sources led to substantial negative environmental and social impacts (e.g. water shortage and seawater intrusion, flood risk, water pollution). The paper discusses the case study of the Pontine bioregion which includes all these aspects. In the Municipality of Latina, located at the centre of the Pontine bioregion, a project co-funded by the EU (Upper project-Urban Innovative Actions) aims to define a bioregional structure based on the integration of ecological networks, mobility networks and new forms of public-private partnership.
\end{abstract}

Keywords: infrastructures, bioregion, heritage, structural invariants, commons, social-contracts.

\section{INTRODUCTION}

In the EU, green Infrastructure strategy, the Green Infrastructure (GI) is defined as "a strategically planned network of natural and semi-natural areas with other environmental features designed and managed to deliver a wide range of ecosystem services. It incorporates green spaces (or blue if aquatic ecosystems are concerned) and other physical features in terrestrial (including coastal) and marine areas. On land, GI is present in rural and urban settings" [1]. In a recent review on the implementation of the EU GI strategy, it is stated that the Natura 2000 network is the "backbone" of the GI, together with "natural and semi-natural spaces outside Natura 2000, such as parks, private gardens, hedges, vegetated buffer strips along rivers or structure-rich agricultural landscapes with certain features and practices, and artificial features such as green roofs, green walls, or eco-bridges and fish ladders" [2]. The same review highlights that although GI are promoted in the EU Urban and Regional Policy and several Member States established national ecological networks GI are still limited at EU level. The review concludes that GI are mainly implemented at a small scale, neglecting their potential economic and social benefits [2]. This conclusion is reflected the activities undertaken by the Member States [3] which are interesting and innovative but are mainly 
complementary to other more consolidated sectors and intervention policies (e.g. energy policies), demonstrating a "fragmented" and local application of the green infrastructure concept, and giving little attention to the complexity and the large scale relevance (regional, national and transboundary nature) of the ecological networks. From the experience of the Green Crown of Turin (Corona Verde di Torino) which worked on the regional scale it emerges that in the collective imagination the green infrastructure refer to parks and natural conservation, without grasping their environmental restoration function, morphology, offer of integrated services but also of local development [4]. The paper discusses the application of the bioregional theoretical framework for an integrated and multi-level deployment of Green and Blue Infrastructures (G\&BI). It first provides a review of the structural invariant concept in the bioregional vision and after explores the potential of social contracts for G\&B Infrastructure planning and design focusing on water infrastructures. In Sections 4 and 5 the paper analyses case studies from the Upper project to characterise how the bioregional approach experimentation can emerge and evolve into the integration of ecological networks, mobility networks and new forms of public-private partnerships. The paper concludes that to achieve an effective and sustainable distribution of G\&BI the combination of the bioregional vision with social contract strategies is most promising to build and effective integrated territorial approach.

\section{STRUCTURAL INVARIANTS OF A BIOREGION}

\subsection{The bioregional vision}

The bioregional vision as we know it, has its cultural roots in Europe and the United States USA in the second half of the nineteenth century, but the first definition of bioregion was formulated by Berg and Darsmann [5] in the late 1970s. This definition focuses on an integrated vision of natural features and of how communities have historically interpreted their relations with the environment rather than on ecological determinism, "In declaring that it will be reinhabitants rather than scientists who define 'home place', bioregionalism was cut forever from the tether of a more sterile biogeography" [6]. Two essential environmental and social issues emerge: the disconnection between humans and natural environment; the search for constructive strategies to link the protection of social networks and economic conditions with the pragmatic use [7] of planning tools or environmental interventions [8]. Furthermore, three main currents of thought can be highlighted [9]: the ecocentric founded on a deep ecological morality and an environmental philosophy that promotes interspecific equity, rejecting the dichotomous view of human beings and nature; the scientific-managerial based on the control and manipulation of the non-human environment, it replaces the local knowledge with external logic aiming at conservation of sensitive areas in favour of economic growth; the socio-environmental that highlights the contradictions of the dominant modes of production, re-evaluating the local knowledge and the ethics of the places. Only the latter is adequate to protect biodiversity and addressing individual and collective social and environmental justice issues.

\subsection{Bioregional citizenship}

In this perspective the bioregional citizenship concept enable to "sees beyond a physically defined bioregion, recognises the emotional ties people feel beyond their immediate living space, and includes environmental justice as a useful concept to advance the bioregionalist agenda" [9]. 
This concept is particularly appropriate to face the new phase of urban regionalization or the new regionalism [10]. It is no longer enough to interpret the condition of the contemporary spatial development with the idea of a metropolis that grows progressively incorporating the small centres. The urban expansion is no more based only on contiguity or commuting to and from a metropolitan centre. New settlements are generally composed by widespread residential or microproductive urbanization of agricultural areas (sprawl), where tertiary functions as shopping malls or high added value services are located. This dynamic is produced by what Soja [11] calls synechism, that is a system polycentric settlements of the urban region that works as an entity that includes the metropolitan city and it not only under his influence. In Italy, the bioregionalist approach has been recently integrated into urban and regional planning, putting emphasis on the ability of the bioregion to self-sustaining through a new coevolutionary relationship between inhabitants-producers and the territory; a relationship that is based on shared and community-based heritage values and commons [12]. This approach acknowledges that contemporary urbanization process concerns the whole urban region including cities and towns. From the denser urban fabrics of the metropolitan areas to the discontinuous rural settlements on remote inner areas, a plural and multicentric vision contribute to rebuild the urbanity through new synergic rural-urban relationships [12].

The bioregional perspective is a promising conceptual framework addressing the fragmentation in the implementation of G\&BI projects and plan as well as of their integration into the planning process. It also provides an analytical framework of the new urban regionalism starting from some reference points:

- the physiographic structures and the characters left by settlements evolution are the heritage that provides or will provide retro-innovation elements for alternative transformation dynamics rather than passive determinants of the settlement organization;

- the ability of the inhabitants to recognize the both physical and immaterial territorial heritage, is the main factor of regional performance and the key catalyst for increasing global and local interaction.

\subsection{The concept of structural invariant}

From the two previous considerations two lines of research emerge. The first considers natural elements and anthropic "sediments" that characterise the landscape by combining nature and culture. These "sediments" are often recognized as heritage to be protected and preserved and each country determines how to do it. In Italy, heritage protection and conservation have a remarkable tradition and in the last three decades a significant innovation has taken place in landscape and urban planning.

The concept of structural invariant has become a point of reference which, mainly from the Tuscany region, has spread to the other Italian regions.

By structural invariants the law of the Tuscany Region means the specific characteristics, the generative principles and the rules that ensure the protection and reproduction of identified territorial heritage components. Characters, principles and rules concern: a) the morphotypological and landscape aspects of the territorial heritage; b) the relationships between the constituent elements of the territorial heritage; c) the generative, utilization, maintenance and transformation rules of the territorial heritage which ensure its persistence. The identification of structural invariants concerns the whole territory, including its derelict parts (Art.5 of the Regional Law n.65/2014). The protection of these elements significantly contributes to shape the territory but it is not sufficient to achieve positive results; the 
relationships between the territory itself and the invariants are neglected, leading to the loss of its structural values and to its transformation into a "museum object".

The second line of research concerns the way in which human beings move, use, interact and enjoy living in a space. It is necessary to investigate the living environments not only through sociological and ethnographic analysis but also through the study of population mobility which in Italy is highly connected the definition of labour market areas (e.g. the Made in Italy industrial districts) [13] as the main references for the delimitation of a bioregion. More than a new administrative district, this delimitation is recognising the boundaries of a living environment that contribute to build a bioregional citizenship and territorial heritage. This recognition tends to be limited to accessibility networks, spaces of production, and service or functions. Although leisure and recreational services may be located in protected natural areas they exclude large portion of the bioregion leaving marginalized and abandoned spaces to polluting and illegal uses damaging the "sediments" of the territorial heritage and its relationships with the context. G\&BI are a suitable tool re-establishing the links between context and "sediments" if there are not considered as a mere replacement of grey infrastructure. Nature Based Solutions (NBS) become effective building blocks of G\&BI, if their technologies integrate environmental efficiency, and culture to rediscover environment, landscape, and paying attention to their systemic relationships G\&BI become the structure of a bioregion affecting both the physical structure and the collective image.

\section{EXPLORING SOCIAL-CONTRATCS FOR GREEN AND BLUE INFRASTRUCTURES}

\subsection{G\&BI approach and the role of the water resource}

The emphasis on green and blue connections at regional scale is frequently linked to ecological networks end related ecosystem services. Networks and particularly green corridors are considered with multiple functions such as climate change adaptation, water management and drainage, biodiversity conservation carbon sequestration, leisure and recreational space. Despite its regional accent G\&BI approach promotes focus on natural processes, on connectivity and multifunctionality, and involves collaboration across disciplines. It shifts the attention of planning from single functions such as drainage, leisure conservation neglecting the natural processes, to synergizing of knowledges, integrating ecosystems services [14], [15], and ecological network language and theory. Integrating the (bio-)physical dimensions with the on socio-cultural, institutional, and political conditions lead also to identify a series of barriers for G\&BI uptake such as the lack of economic and social evaluation and the lack of integration with other urban (or spatial) dimensions. If some authors argue that economic value with its benefits and appropriate finance methods should be introduced to develop credible business projects for informed decision-making of local authority [16], others maintain that economic evaluation of ecosystem services and G\&BI impacts lead to the commodification of fundamental non-renewable resources undermining their sustainability and equity dimension [17]. The adoption of a bioregional "scale" and approach can contribute to overcome this dichotomy linking the ecological dimension to the local economic dimension. In addition, given the complexity and the conflicts among socio-cultural, bio-physical, economic, institutional and political actors the bioregional vision can be an affective framework for decision-making and projects/initiatives development and implementation, providing a shared territorial platform and sets of values based on the local economic, environmental, socio-cultural and political context. 
In the urban region the water represents a natural resource where the nature-human interaction needs to be particularly well managed to ensure a sustainable and inclusive blue and green infrastructure (e.g. flood risk, water shortage, water pollution). In response to resource constraints, growing populations, and climate change, different approaches for urban water sustainability have been developed with focus decentralization, integration, resource efficiency, affordability, participation, or restoring natural systems [18].

The privatisation of water services and infrastructure is acknowledged to be having a major impact on the governance of water and on its physical and social impacts, leading to exploitation, and the exclusion of social and ecological interests in urban water decision-making [19], [20].

\subsection{A new governance through social-contracts}

The transition towards new governance regime and the reorganisation of the agency behind the reconfiguration of the urban infrastructure has been barely considered in the planning and design of G\&BI. If attention has been given to the adaptation of infrastructure and services to privatisation or liberalisation and partially to the reconfiguration of the triad provider, regulator and user, the range of actors and technologies working in-between this triad as "intermediaries" is neglected [21]. Integrating this in the bioregional vision helps to understand how changes in one set of actors, activities process has implications elsewhere in water sector for instance. The reconfiguration of the water infrastructure dependent on perceptions, values and cognitions and is often associated to normative notions to describe desirability of transformation. Actors shapes the infrastructure system through agency and governance, and the type of political-, value- and power-based processes. The transformation processes rebalance rights and responsibilities between the different actors; an infrastructure system mediating the relationship between resources, providers and users/co-providers [22] is also distributing rights and responsibilities, is based on and is shaping the dynamic interaction between actors, building a system of rules and social networks. Those interactions can be translated into a "social contract" such as a plan which can constrain or limit public authority and power and protect citizens rights, according to specific assumptions on rights and responsibilities. In addition, a "social contract" allows to experiment with new forms of commons management [23]. The River Contracts are the result of national and European environmental regulatory frameworks. The river contracts were introduced in France and Italy in the early ' $90 \mathrm{~s}$ in response to specific environmental and water management issues defined during the 1992 Rio Summit. The introduction of different types of land pacts or contracts is meant to integrate the complexity of the natural environmental and of the actors involved in their management and governance and improve community participation. River Contracts are voluntary tools grouping different actors and stakeholders in a legal entity for a sustainable management of water resources along a water basin. They are strategic and negotiated planning documents, aiming to promote the enhancement of river environment e.g. safeguarding from flood risk contexts, and the involving a wide of local, regional or national institution and stakeholders across different scales and sectors.

In Sections 4 and 5 is illustrated the case study of the Pontina bioregion. In particular, Section 4 discusses how the local authority drafted the Upper project, highlighting the problems that are emerging to overcome the traditional grey infrastructure approach. Section 5 investigates how the coastal and river contracts introduced in the Pontina region can demonstrate their potentials and shortcoming as a planning tool for promoting and integrated bioregional approach for G\&BI. 


\section{DEVELOPING THE UPPER PROJECT IN THE PONTINA BIOREGION}

\subsection{Objectives and risks of the Upper project}

The case study of the Pontine bioregion allows to apply theoretical reflections above through various research experiences and including the Upper project. It's project co-funded by the EU Urban Innovative Actions, an initiative promoting pilot projects for sustainable urban development. The Municipality of Latina is the promoter of the project that is ongoing (it will end in August 2022) and the authors of this paper are member of the project working group of Sapienza University and external expert on environmental planning and water infrastructure in coastal settlements. The Upper project has as primary objective the construction of 3 productive parks for the production of plants and the definition of advanced Nature Based Solutions (NBS) to be applied on 8 pilot sites. Upper is a complex and innovative project that develops on three integrated intervention lines: that of environmental requalification and innovation of green technologies implicit in the NBS concept; the economic one aimed at promoting both the formation of startup companies dedicated to NBS and the development of a market in the Green Public Procurement of NBS making the town of Latina become a reference for the other municipal administrations of the bioregion; the social one linked to the insertion into the world of work of disadvantaged inhabitants through training courses on the care of plants and the experimentation of new models of Public Private Partnership (PPP) concerning not only the companies that will manage the three productive parks but also the citizens who they may be involved in the management of the testing areas after their renovation. The test sites and productive parks are located in different types of areas, almost all within the urban centre but with different characteristics not only for the type of soil, more or less rich in vegetation or completely waterproofed, but above all for the context. In particular (see Fig. 1): a) green areas equipped for recreation (n.2); b) green areas making up the central place of a square (n.5); c) degraded green areas in undefined public spaces (n.3-4); d) degraded areas on the edge of urban fabrics (n.6); e) areas bordering urban areas with significant levels of naturalness (n.9); f) areas adjacent to water courses with or without hydraulic risks (n.1-8-10); g) areas for car parks with or without trees (n.2-7). The social contexts of the areas are also different from one another, ranging from areas with affluent populations to areas with most vulnerable citizens because they are migrants or belong to the Roma ethnic group. This physical and social variety of the areas allows different types of applications which, if they give good results, can be used in many other cities, at regional and national but also European level.

The integration between the three areas of intervention is has been showing some problematic issues and is likely to have a negative impact on implementation times and on the quality of the entire project. The renovation of the areas is managed by Latina Municipality through public contracts which are quite complex and whit uncertainties and possible bureaucratic hitches due also to the anti-corruption rules. This situation undermines the innovation potentials of the projects with a prevailing traditional approach. The new green infrastructure are considered as grey infrastructure in the design, restricting citizens' participation and social learning process. The other problematic node is the difficulty of creating start-up companies in a new market and in a complex regulatory and bureaucratic. Both issues need a broad definition of NBS and a transdisciplinary multisectoral approach including extensive information and dissemination activities closely connected to the areas of experimentation. 


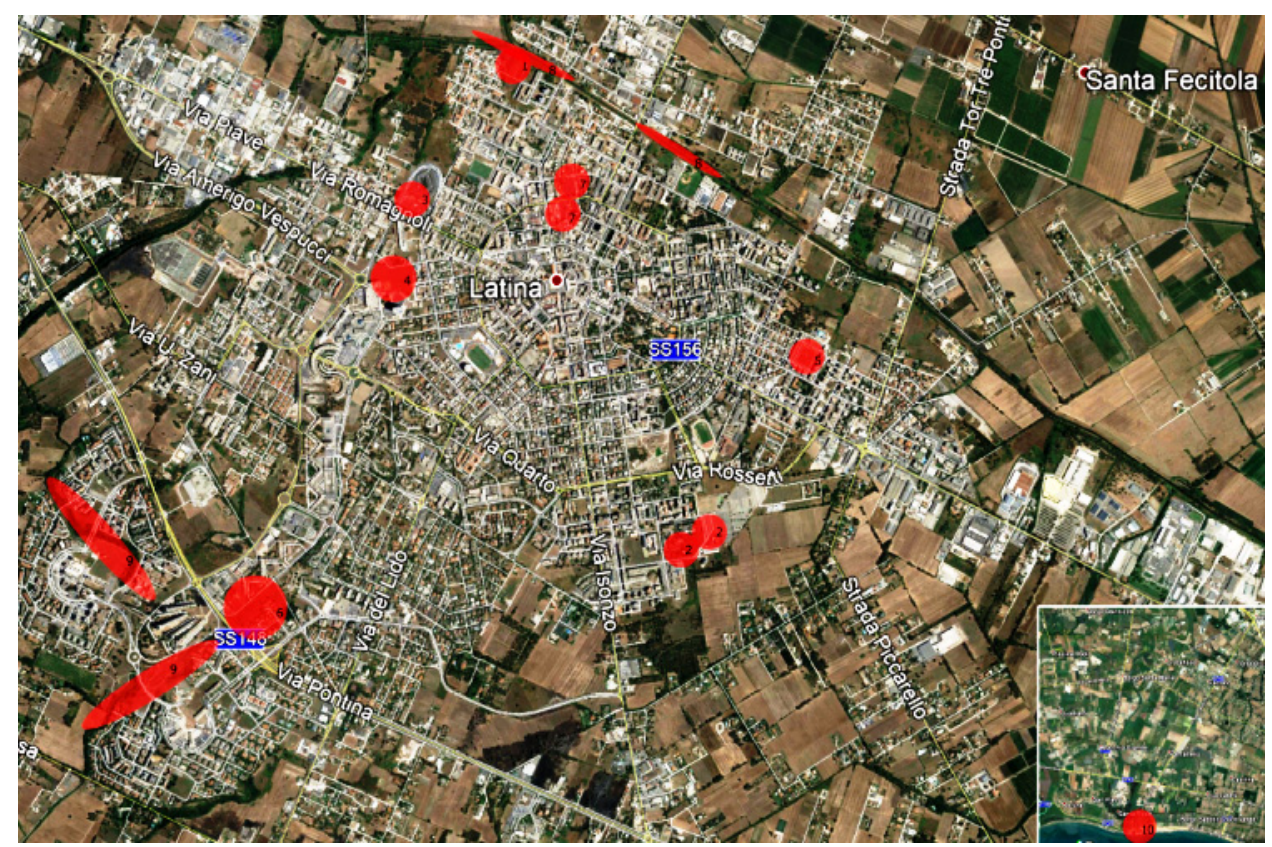

Figure 1: The areas of the Upper project. (Source: Comune di Latina [24].)

\subsection{NBS as systemic "connectors" of the Pontine bioregion}

The bioregional vision is fundamental to address these issues. First, a design of "truly green" areas, with NBS not limited to technological solutions without relations with the context, cannot be separated from the entire abiotic system and imbalances induced by anthropic pressures; from the core areas (sources of biodiversity) which must be linked to areas with poor naturalistic value but strategic to build an ecological network. In the case of the Pontine bioregion and the territory of the Municipality of Latina these aspects are really important. The integral reclamation has profoundly altered the ecosystems, reducing forest cover, replacing most of the hydrographic network with artificial water bodies, canals and water pumping systems. The foundation of Latina (formerly Littoria) in 1932, as well as the other "new" towns of Sabaudia and Pontinia, was not envisaged in the initial planning of land reclamation. The plan was supposed to include only the hydraulic works and the division into farms, as well as the assignment of land and housing to settlers who would have access only to services for rural life in nearby rural villages. The success obtained in giving a new structure to the territory led to the formation of towns that were meant to exemplify the Fascist ideal of the rural town. The rural town shouldn't be "contaminated" by urban growth and far from the railways that could have facilitate development. However, Latina was soon an anomalous with the role of provincial capital acquired in 1934 and its tertiary endowment. After WW2, the Agro Pontino became one of the hubs of a new industrial development thrust promoted by the Cassa per il Mezzogiorno (the national fund for development of Southern Italy). Although the number of inhabitants has grown significantly (Latina is now the second largest city in Lazio, with over 125,000 residents), the crisis of the Pontine manufacturing industries and the abolition of the Cassa per il Mezzogiorno have diverted economic growth towards the tertiary sector and the transformation of agriculture towards more profitable 
segments such as fruits and vegetables. On the other hand, building expansion has grown. Along with the construction of shopping centres and tertiary functions integrated with residential housing, sprawl settlements have developed. In addition to consuming land and compromising agricultural uses, sprawl modifies the landscape and the identity of the territory. The city of Latina has therefore become the most important centres of the homonymous Province and of the Pontine bioregion constituted (see Fig. 2) by the Pontine plain, by the western side of the Lepini mountains, by the Amaseno valley. All these morphological elements are closely connected by the hydrographic network and the groundwater in the diversity of the geological conformation: limestone that of the mountain area, marsh that of the plain, dune that of the coastal belt. The bioregion, with the other cities of Terracina, Sabaudia, Cisterna di Latina, San Felice Circeo and the centres of the Lepini mountains is the main living environment for about 300,000 inhabitants who, from the analyses on mobility, also maintain significant relationships with Rome and with the contiguous areas to the bioregion (transition zone of the bioregion). Like Latina, the entire plain the bioregion is affected by urban sprawl, industrial pressures and intensive agriculture activities compromising the eco-systems.

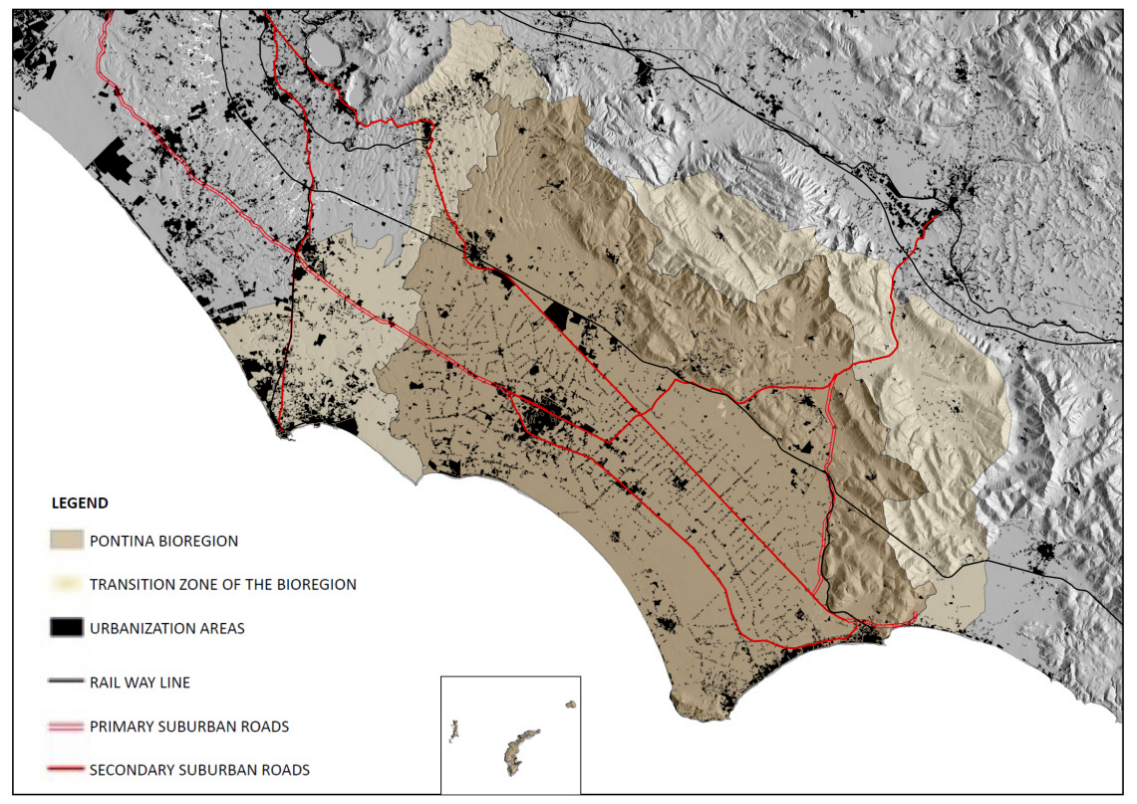

Figure 2: The Pontina bioregion. (Source: Bodoni et al., 2018 [25].)

\section{INTEGRATING WATER INFRASTRUCTURES AND COMMONS THROUGH SOCIAL CONTRACTS}

5.1 Water infrastructures at the centre of the relationship between nature and culture in the Pontine bioregion

Water infrastructure are particularly relevant to the history and future development of the Pontina region, ability to continue residing, farming and conducting other economic and social activities, depends on a complex pumping and drainage system that affected by 
urban expansion and environmental change. The attempt to drain the marshes in the Pontina Plain date back to the Roman Empire (or earlier). Extensive land reclamation work was performed periodically and the "integral land reclamation" (bonifica integrale), including not only the hydraulic sector but also the human and health sector, was conducted between 1926 and 1939. The result was a complex system of channels and water pumps collecting and driving the water from the mountains to the sea trough the coastal plain. Drainage, defensive and irrigation works, together with roads construction land and mountain improvement, changed the bio-physical nature and the land governance of the area creating a very sensitive environment. The vulnerability of the Pontina plain is currently exacerbated by progressive artificialisation of the natural environment, soil sealing and urban expansion. The intensification of human activities which took place in the first decades of the twentieth century, progressively moved from agriculture to coastal tourism and to the development of industrial settlements. This increased the exploitation of the groundwater resource, as little attention was given both to the anthropogenic impact on water resources and land reclamation water infrastructure and on the connection and interdependencies between green and natural areas and urban and rural settlements. The privatisation of water services, competitive uses of water and the over exploitation of water sources led to substantial negative environmental and social impacts (e.g. water shortage and seawater intrusion). Hence there is a need to reconcile interactions between nature and human society and but also to understand the implications of the socio-technical changes.

\subsection{The social contracts of the Upper project}

A bioregional vision is considered particularly effective in a context where the water cycle and the equilibrium between fresh water coming from the Lepini mountains and the sea water is considered as one sensitive environment and complex socio-technical system.

In the Upper project the adoption of a bioregional "scale" and approach aims to integrates ecological dimension to the local economic dimension engaging local enterprises with the re-connection, both at the city and regional scale, of the green and blue features/elements of the Pontina Region. The project has the ambition to both promote local economic development and rediscovery the cultural and historical value of the 8 selected pilot sites building join initiatives and synergies between socio-cultural, bio-physical, economic, institutional, and political actors. The Upper project focus on derelict green areas and try to reconnect them to the urban environment at the local and bioregional scale.

Three out of eight sites selected for the testing and demonstration of NBSs are conceived to effectively link blue and green infrastructure as they are beside an important artificial water body, the Canale Acque medie, a reclamation channel (area 8), a residual natural water body the Fosso Paoloni (area 9) and on low laying an areas (p.p. 3) surrounded by water streams and at the side of the Oasis Life Rewetland, the site of an phytodepuration experimental project realised by the Province administration during the implementation of the Rewetland Life+ project. The three sites are experimental sites where innovative NBSs will be tested, the latter includes also one of the productive parks for the plants selections and productions and the definition of advanced NBSs. The NBSs Strategy builds on previous collaborative governance process and on water and Greens infrastructures networks implemented by Latina Province both in statutory planning (Water Monitoring project, and the Provincial Territorial Coordination Plan 2003) and in innovative projects co-funded by the EU such as the Life+ Rewetland project (2010-2014) [26] and the Life Greenchange project [27] started in 2018. These Life projects together with the Interreg Med Coasting project led to the formulation of River Contracts (CdF) and a Coast Contract started between 2016 and 2019 
with the aim of activating a multilevel territorial governance process through the involvement of public and private actors such as the Province of Latina, the Municipalities, the XIII Mountain Community of the Lepini and Ausoni Mountains, the Land Reclamation Consortium of the Agro Pontino, the trade associations as well as the sports, environmental and cultural associations [28].

A large group of stakeholders directly involved in the realization of the project will include: Labsus Association, Isimpact Association, Association Magma, Lazio Innova spa, the networks "Latina 2032" and Coordination Vialibera, as well as the neighbourhood associations "Porta Nord-Campo Boario" and "Parco degli Elleni". Labsus Association, specialized in participatory and citizenship governance, will take part in the Co-design seminars applying its extensive experience in collaborative paths and local social contract which can integrate and expand the above-mentioned experience. The project will also establish of a broad stakeholder steering group to contribute to the progress and monitoring of the project.

The integrated governance system implemented through the cooperation between the River and Coast Contracts and the Upper pilot projects participated design and implementation, is an opportunity to involve all public and private subjects interested in the management and use of the resource at local level, in order to promote a cross-sectoral and multi-scale approach and active participation of the actors, to strengthen collaboration between Municipalities and other public bodies and private stakeholders in the planning, design and management of G\&BI such as river basins, shorelines, woodlands etc.

\section{CONCLUSIONS}

The G\&BI deployment is limited by small scale, fragmented interventions, and integrated approaches paying attention to the economic and social benefits and to the commons green and blues resource pools, is little explored. The bioregional approach and the social contracts represent an opportunity for integrating the multiple dimensions of G\&BI into urban and regional planning.

Particularly, the structural invariant concepts translate in increasing the awareness, ownership and relevance of green and blue natural resources and infrastructure (e.g. rivers or shorelines) as commons. The social contracts on the other side enable shared decisions and promote processes where residents and other relevant stakeholders become the key actors in the design and management of G\&BI and commons. This clearly emerge in the Upper project where the demonstration sites are areas where residents and enterprises actively engage in decision-making, actions and management. This will ensure long-term the sustainability of the initiatives avoiding that the areas are abandoned after the realisation of the EU project.

The bioregional framework and the social contracts strategy are little explored and leave open a series of questions such as: how to deal with the power relations and conflicts between the different actors and stakeholder involved in the social contract; how to meet the need for environmental and economic resilience in a fast changing environment exposed to environmental, economic, health crisis or disruptive changes; how to adopt a flexible and transformative approach to cope with high uncertainty and avoiding losses; how better orient public-private partnership to work for the commons, e.g. how move towards green public procurement and corporate social responsibility for supporting G\&BI. The Upper project gives the opportunity to experiment various forms of social contract keeping in mind the structural invariants of the bioregion to explore the problematic issues mentioned above. However, a bioregional vision must be maintained to scale up and connect local initiatives, coordinating between the local social contracts and creating a link with the bioregional citizenship. 


\section{REFERENCES}

[1] $\operatorname{COM}(2013), 249$ final, Green Infrastructure (GI) - Enhancing Europe's natural capital, Brussels, p. 3, 6.5.2013.

[2] $\operatorname{COM}(2019), 236$ final, Review of progress on implementation of the EU green infrastructure strategy, Brussels, p. 1, 10, 24.5.2019.

[3] SWD(2019), 184 final, Additional information on the review of implementation of the green infrastructure strategy, Brussels, 24.5.2019.

[4] De Rossi, A., Una regia "d'azione" territoriale a partire da corona verde. L'infrastruttura verde per l'area metropolitana torinese, Corona Verde 2025, I Quaderni di Torino Strategica, n. 1, 2016.

[5] Berg, P. \& Darsmann, R., Reinhabiting California. Ecologist, 7(10), pp. 399-401, 1977.

[6] Aberley, D., Interpreting bioregionalism. A story from many voices. Bioregionalism, ed., M.V. McGinnis, Routledge: London and New York, 1999.

[7] Forester, J., On the theory and practice of critical pragmatism: Deliberative practice and creative negotiations. Planning Theory, 12, pp. 1-18, 2012.

[8] Gray, R., Practical bioregionalism: A philosophy for a sustainable future and a hypothetical transition strategy for Armidale, New South Wales, Australia. Futures, 39, pp. 790-806, 2007.

[9] Gilbert, L., Anders Sandberg, L. \& Wekerle, G.R., Building bioregional citizenship: The case of the Oak Ridges Moraine, Ontario, Canada. Local Environment, 14(5), pp. 387-401, 2009.

[10] Soja, E.W., Accentuate the regional. International Journal of Urban and Regional Research, 39(2), pp. 372-381, 2015.

[11] Soja, E.W., Postmetropolis. Critical Studies of Cities and Regions, Blackwell Publishers: Oxford and Malden, MA, 2000.

[12] Magnaghi, A., Il progetto della bioregione urbana. Regole statutarie e elementi costruttivi. La regola e il progetto Un approccio bioregionalista alla pianificazioneterritoriale, ed. A. Magnaghi, University Press: Firenze, 2014.

[13] ISTAT, I sistemi locali del lavoro, statistiche report 2014. http://www. istat.it.

[14] Lennon, M., Grasping green infrastructure an introduction to the theory and practice of a diverse environmental planning approach. The Routledge Companion to Environmental Planning, eds, S. Davoudi, R. Cowell, I. White \& H. Blanco, pp. 277$288,2019$.

[15] Lennon, M. \& Scott, M., Delivering ecosystems services via spatial planning: reviewing the possibilities and implications of a green infrastructure approach. Town Planning Review, 85(5), 563-87, 2014.

[16] Van Oijstaeijen, W., Van Passel, S. \& Cools, J., Urban green infrastructure: A review on valuation toolkits from an urban planning perspective. Journal of Environmental Management, 267, pp. 1-10, 2020.

[17] Swyngedouw, E., Circulations and metabolisms: (hybrid) natures and (cyborg) cities. Science as Culture, 15(2), pp. 105-121. 2006. https://doi.org/10.1080/09505430600707970.

[18] Bell, S.J., Frameworks for urban water sustainability. WIREs Water, 2020. https://doi.org/10.1002/wat2.1411.

[19] Gandy, M., Rethinking urban metabolism: Water, space and the modern city. Taylor \& Francis Online, 8(3), pp. 363-379, 2004. https://doi.org/10.1080/ 1360481042000313509. 
[20] Swyngedouw, E., Circulations and metabolisms: (hybrid) natures and (cyborg) cities. Science as Culture, 15(2), pp. 105-121, 2006. https://doi.org/10.1080/09505430600707970.

[21] Guy, S., Marvin, S., Medd, W. \& Moss, T., Shaping Urban Infrastructures: Intermediaries and the Governance of Socio-technical Networks, Earthscan: London, 2011.

[22] Van Vliet, B., Chappels, H. \& Shove, E., Infrastructure of Consumption: Environmental Innovations in the Utility of Industries, Earthscan: London, 2005.

[23] Ostrom, E., Governing the Commons: The Evolution of Institutions for Collective Action, Cambridge University Press: Cambridge, 1990.

[24] Comune di Latina, Upper Project. http://www.comune.latina.it/le-mappe/.

[25] Budoni, A., Martone, M. \& Zerunian, S. (eds), La Bioregione Pontina: Esperienze, Problemi, Linee di Ricerca per Scenari di Futuro, Edizioni SdT: Firenze, ebook open access 2018. http://www.societadeiterritorialisti.it/2016/01/17/collana-qricerche-estudi-territorialistiq/.

[26] Rewetland, Widespread introduction of constructed wetlands for a wastewater treatment of Agro Pontino, Provincia di Latina. http://www.rewetland.eu/. Accessed on: 31 May 2020.

[27] Life Greenchange, Contratti di fiume della Provincia di Latina, Provincia di Latina. http://lifegreenchange.eu/cdfagropontino/. Accessed on: 23 Jun. 2020.

[28] Magaudda, S., Muccitelli, S. \& Pozzi, C., La governance ambientale dell'Agro Pontino: dalla rete ecologica ai Contratti di Fiume. Reticula, 22, pp. 57-67, 2019. 